


\title{
Fairness in Winner-Take-All Markets*
}

\author{
Björn Bartling ${ }^{1,2} \quad$ Alexander W. Cappelen ${ }^{1} \quad$ Mathias Ekström ${ }^{1,3}$ \\ Erik Ø. Sørensen ${ }^{1} \quad$ Bertil Tungodden ${ }^{1}$
}

May 20, 2018

\begin{abstract}
The paper reports the first experimental study on people's fairness views on extreme income inequalities arising from winner-take-all reward structures. We find that the majority of participants consider extreme income inequality generated in winner-take-all situations as fair, independent of the winning margin. Spectators appear to endorse a "factual merit" fairness argument for no redistribution: the winner deserves all the earnings because these earnings were determined by his or her performance. Our findings shed light on the present political debate on redistribution, by suggesting that people may object less to certain types of extreme income inequality than commonly assumed.
\end{abstract}

JEL Classification Numbers: C91, D63

Keywords: Winner-take-all reward structures, fairness, income inequality

1) Department of Economics, NHH - Norwegian School of Economics

2) Department of Economics, University of Zurich

3) Research Institute of Industrial Economics (IFN), Stockholm

\footnotetext{
${ }^{*}$ We thank Anna Blomkvist, Christian Braathen, Anne-Lise Breivik, Daniel Flokenes, Easa Tabrizi, Emilie Viung, Felix Morency-Lavoie, Ida Kjørholt, Maria Seidel, Marta Bakke, Sebastian Fest and Valeria Shuvatova for excellent research assistance. We also thank Marcel Preuss, Matthias Sutter, and numerous seminar and conference participants for useful comments. The study was administered by FAIR-The Choice Lab and received support from the Research Council of Norway through its Centres of Excellence Scheme, FAIR project No 262675 and research grant 236995, and the NORFACE Welfare State Future Program.
} 


\section{Introduction}

In important economic settings, small differences in performance give rise to large differences in earnings. Winner-take-all reward structures have long been common in sports, entertainment, and the arts, where the return to being a "superstar" outshines the return to being just below the top (e.g., Rosen, 1981; Frank and Cook, 1995). Technological advancement and removal of trade barriers enable unlimited reproduction and cheap distribution of the "best" goods and services in many markets, which renders it increasingly common that a small number of individuals receive a disproportionate share of the overall surplus. Indeed, Atkinson, Piketty, and Saez (2011, p. 59) argue that one explanation for "the rise in top earnings shares in a number of countries in the second half of the postwar period is provided by the superstar theory of Rosen (1981).'1

This development is mirrored in the current debate on income inequality, where much attention is given to the increasing share of income going to the top one percent of income earners (e.g., Piketty and Saez, 2003; Alvaredo, Atkinson, Piketty, and Saez, 2013). A common premise in this debate has been that it is unfair that the top income earners receive an increasingly disproportionate share of the income in society (Atkinson et al., 2011, p. 7), but there is a lack of evidence whether people actually agree with this premise.

In this paper, we report from, to our knowledge, the first experiment to study people's fairness views on extreme income inequalities that arise under winner-take-all reward structures. In our main winner-take-all treatment (WTA), subjects in the role of third-party spectators could redistribute earnings between two real workers, who had completed a task in an online labor market. The two workers had chosen to work under a winner-take-all reward structure, which is defined by two features:

1. Only the winner earns money.

2. The winner's earnings only depend on his or her performance.

Importantly, this reward structure implies that the winning margin, i.e. how much better the

\footnotetext{
${ }^{1}$ Alfred Marshall described this development in his Principles of Economics already a century ago: "A business man of average ability and average good fortune gets now a lower rate of profits on his capital than at any previous time; while yet the operations, in which a man exceptionally favoured by genius and good luck can take part, are so extensive as to enable him to amass a huge fortune with a rapidity hitherto unknown. The causes of this change are [...] the development of new facilities for communication, by which men, who have once attained a commanding position, are enabled to apply their constructive or speculative genius to undertakings vaster, and extending over a wider area, than ever before" (Marshall, 1920, 8th edn., Book VI, Chapter XII, Paragraph 11).
} 
winner is than the loser, does not matter for the earnings distribution.

In our experiment, the spectator was informed about the performance of the two workers and how the workers' earnings were determined. The spectator was then asked to decide how much of the winner's earnings to transfer to the loser, and this decision determined the income of the two workers. Since the spectators had no personal stake in the decision, we assume that their distributive choices reflect what they view as the fair income distribution in a winner-takeall situation (Cappelen, Konow, Sørensen, and Tungodden, 2013a; Mollerstrom, Reme, and Sørensen, 2015).

Conflicting fairness arguments exist in a winner-take-all situation. On the one hand, the winner performed better and his or her performance determined the earnings available for distribution, independent of the performance of the loser. This may be considered a "factual merit" fairness argument for no redistribution: the winner deserves all the earnings since these earnings were determined by his or her performance. On the other hand, the earnings available for distribution would not have been zero had the winner not produced anything; it would then have been determined by the performance of the loser. This may be considered a "counterfactual merit" fairness argument for redistributing to the loser: the loser deserves an equal share of the earnings that would have been assigned to him or her in the counterfactual situation where the winner had not produced anything, while the winner also deserves the additional earnings created by his or her performance being greater than the performance of the loser in the actual situation. An important difference between these two fairness arguments is that "factual merit" implies that nothing is transferred to the loser, independent of the winning margin, while "counterfactual merit" implies that the amount transferred is increasing in the loser's performance.

We compare the distributive behavior of the spectators in our main winner-take-all treatment to the behavior of spectators in a base treatment (Base), where the earnings distribution for a given pair of workers was imputed from a yoked pair in the WTA treatment and where one of the two workers was randomly drawn, independently of performance, to get all the earnings. The inequality in earnings is therefore identical in the two treatments, but in the Base treatment there is no fairness argument based on merit for one of the workers receiving more income than the other. To shed further light on why people accept inequality in a winner-take-all situation, we implement two additional treatments with the winner-take-all structure. The treatment WTANo Choice is identical to the WTA treatment except that the individuals had no choice of reward scheme but were directly placed under the winner-take-all reward structure. The treatment 
WTA-No Expectations is identical to the WTA-No Choice treatment except that the workers are not informed about how their earnings are determined. In all treatments, the spectators had complete knowledge about the information given to the workers in the respective treatments.

Our study offers three main findings. First, we find that extreme inequality in earnings is largely considered fair when it derives from a winner-take-all reward structure: a majority (58\%) of the spectators do not transfer anything to the loser in the WTA treatment, while only a very small minority (10\%) accepts such an extreme inequality in the Base treatment, where the winner is randomly determined. Second, we do not find evidence of the spectators invoking a "counterfactual merit" fairness argument in their distributive decisions: the transfer to the loser does not depend on his or her performance. This suggests that a large share of the spectators endorse the "factual merit" fairness argument and, consistent, with this we find that the fraction of spectators who give everything to the winner is independent of the winning margin. Finally, we show that the acceptance of extreme inequality is also present when we remove the possibility of choice and individual expectations. Many spectators seem to find it fair that the winner gets it all, independent of whether he or she chose to work under these conditions or was aware of the reward structure.

Our findings corroborate Mankiw]s $(2010,2013)$ reflections on individuals' moral intuitions: "My sense is that people are rarely outraged when high incomes go to those who obviously earned them. When we see Steven Spielberg make blockbuster movies, Steve Jobs introduce the iPod, David Letterman crack funny jokes, and J.K Rowling excite countless young readers with her Harry Potter books, we don't object to the many millions of dollars they earn in the process" (2010, p. 36). In line with this, in the experiment we find that spectators endorse that the winner gets all the earnings, even if the performance of the loser is almost the same as the performance of the winner.

Our study contributes to the literature on what people view as a fair distribution and how fairness considerations shape individual behavior (e.g., Fehr and Schmidt, 1999, Konow, 2000; Cherry, Frykblom, and Shogren, 2002; Falk, Fehr, and Fischbacher, 2003; Tyran and Sausgruber, 2006; Cappelen, Drange Hole, Sørensen, and Tungodden, 2007; Konow, Saijo, and Akai, 2009; Almås, Cappelen, Sørensen, and Tungodden, 2010, Cabrales, Miniaci, Piovesan, and Ponti, 2010, Rodriguez-Lara and Moreno-Garrido, 2012; Cappelen, Moene, Sørensen, and Tungodden, 2013b; Durante, Putterman, and Weele, 2014; Bartling, Weber, and Yao, 2015; Jakiela, 2015). A number of papers both in social psychology and in behavioral economics 
have shown that a majority of people appear to view income inequalities as fair if the inequalities are proportional to differences in performance (e.g., Adams, 1965; Walster, Berscheid, and Walster, 1973; Leventhal, 1980; Konow, 2000; Frohlich, Oppenheimer, and Kurki, 2004; Cappelen, Sørensen, and Tungodden, 2010; Cappelen et al., 2007, 2013a). In contrast, we show that in a winner-take-all situation, people accept extreme inequality that is not at all proportional to differences in performance, but rather reflects the fairness view that the winner deserves all the earnings since they were determined by his or her performance, independent of the performance of the loser: ${ }^{2}$ Finally, the results contribute to the political economy literature on redistribution (Fong, 2001; Alesina and Giuliano, 2011), by showing that the present focus on redistribution from the top one percent in society may have less public support than anticipated by the existing literature (Atkinson et al., 2011).

The paper is organized as follows. Section 2 presents the experimental design. Section 3 reports the results, with a focus on the redistributive choices of the third-party spectators. Section 4 concludes.

\section{Experimental Design and Procedures}

We address three questions in this study. First, do people accept the extreme inequality generated by winner-take-all reward structures? Second, do they invoke the "factual merit" or the "counterfactual merit" fairness argument in their distributive choices? Third, do peoples' fairness perceptions depend on the options and information available to the economic actors? To answer these questions, we designed an experiment that consists of a work phase and a redistribution phase. A first set of subjects-the workers-complete a real-effort task in the work phase. Workers are matched into pairs and compensated according to a winner-take-all reward structure, except for in the Base treatment. We elicit fairness views on the earnings distribution in the redistribution phase. To this end, a separate group of subjects-third-party spectators-have to make real redistributive choices. Each spectator is uniquely matched to a pair of workers and can redistribute earnings from the winner to the loser. The spectators' choices in the redistribution phase are our primary interest, but we first explain the details of the work phase.

\footnotetext{
${ }^{2}$ The results also suggest that gender differences in earnings caused by differential performance in winnertake-all markets (e.g., Gneezy and Rustichini. 2004; Niederle and Vesterlund 2007; Almås, Cappelen, Salvanes, Sørensen, and Tungodden, 2016; Samek, 2013, Buser, Niederle, and Oosterbeek, 2014) may largely be viewed as fair.
} 


\subsection{The Work Phase}

We recruited 1198 workers in the online labor market Amazon Mechanical Turk (MTurk). Each worker received USD 2 for participating in the study and could earn additional money in the work phase. We assigned workers randomly to one of four treatments: WTA, WTA-No Choice, WTA-No Expectations, or Base $3^{3}$ The workers' task in all treatments was to solve 24 pattern recognition problems in ten minutes ${ }^{4}$ At the end of the study, the workers were informed about their income from the experiment, but did not receive any further information. In particular, they were not given any information about their absolute or relative performance on the task.

In the WTA treatment, workers could choose between a piece-rate (referred to as Option A), which paid 5 US cents for each correctly solved problem, or having their earnings be determined under the winner-take-all reward structure (Option B). Workers who chose the winnertake-all reward structure were randomly matched in pairs. The better performing worker in a pair (the winner) earned 15 US cents for each problem that he or she solved correctly, the other worker (the loser) earned nothing at all. Thus, the two defining features of a winner-takeall situation are satisfied: only the winner earns money and the winner's earnings are solely determined by his or her performance. The subjects were also told that if they chose the piecerate, the income from the experiment would be equal to their earnings, while if they chose the winner-take-all reward structure, there would be a redistribution phase that might affect the final distribution of income between themselves and the other worker in the pair.

The WTA-No Choice treatment is identical to the WTA treatment, except that workers could not choose between the piece rate and the winner-take-all reward structure, but were directly matched with a random other worker and informed that they would earn money according to the winner-take-all reward structure. The WTA-No Expectations treatment is identical to the WTA-No Choice treatment, except that workers were not informed that they might earn additional money and thus were also not informed about the redistribution phase. They were simply told that their task was to solve 24 pattern recognition problems in ten minutes.

\footnotetext{
${ }^{3}$ We did not allocate workers evenly across treatments. A pilot study showed a low standard deviation in the redistributive choices of spectators in the Base treatment, and we therefore imposed a lower probability of a worker being assigned to this treatment. The primary reason for running the pilot was to calibrate the piece-rates to ensure that a sufficient number of workers opted for the winner-take-all reward structure in the WTA treatment. Further, we had more subjects in WTA than in the other treatments to account for the fact that not all subjects would opt for the winner-take-all reward structure. In sum, we had the following number of workers: 654 in WTA (where 202 workers chose the winner-take-all reward structure), 219 in WTA-No Choice, 217 in WTA-No Expectations, and 108 in Base.

${ }^{4}$ The full set of instructions is in Appendix B, including two examples of the pattern recognition problems.
} 
In the Base treatment, we uniquely matched each pair of workers to a pair of workers in the WTA treatment. We assigned one random worker in the Base pair the same earnings as the winner's earnings in the matched WTA pair. The other worker in the Base pair received no earnings, like the loser in the matched pair in the WTA treatment. In the Base treatment, the workers were simply told that their task was to solve 24 pattern recognition problems in ten minutes, but were not given any further information about the possibility of earning money. A summary of the differences between the four conditions is provided in Table 1.

Table 1: Treatment overview

\begin{tabular}{lccccc}
\hline & \multicolumn{3}{c}{ WTA } & \\
\cline { 2 - 4 } & Main & No Choice & No Exp. & Base \\
\hline Workers have a choice & yes & no & no & no \\
Workers are informed about earnings structure & yes & yes & no & no \\
Earnings are determined by performance & yes & yes & yes & no \\
\hline
\end{tabular}

\subsection{The Redistribution Phase}

We recruited 349 subjects to the role of third-party spectators among the student population at the Norwegian School of Economics. Each spectator received a fixed payment of 150 Norwegian Kroner (about USD 22 at the time of the experiment) for participating in the study. The study was conducted in a computer lab using a web-based interface enabling us to randomize treatments within sessions. We conducted seven sessions, all of which took place on the same day, immediately after collecting the data on MTurk. The workers on MTurk were then paid according to the decisions of the spectators within a few days. The experimental procedure ensured that experimenters could not link decisions to individual spectators.

We randomly assigned each spectator to one pair of workers 5 The spectators then received three pieces of information. First, they were informed about how earnings had been determined for the pair of workers they were assigned to. Second, they were informed about the number of problems correctly solved by each worker-except in the Base treatment, where we only informed the spectators that both workers had completed the task, in order to remove any merit fairness argument for giving more to one of the workers. Finally, the spectators were informed

\footnotetext{
${ }^{5}$ This means that we have slightly more worker pairs (372) than spectators. In WTA-No Choice and WTA-No Expectations, we also had an odd number of workers and thus two workers could not be matched into a pair. These additional worker pairs and the two odd workers are not included in the analysis.
} 
about the earnings distribution. Spectators were then asked whether they wanted to redistribute money from the winner (i.e., the worker with all the earnings) to the loser (i.e., the worker with no earnings), with no default option ${ }^{6}$ Hence, spectators had to make an active choice of whether to leave the earnings distribution unchanged or to redistribute some, or even all of the earnings to the loser. The decisions of the spectators therefore determined the income of the workers.

In the analysis, we focus on the 308 spectators who were matched to pairs of workers who differed in their performance 7 The spectators were on average 22 years of age, 42 percent were female, and 60 percent expressed a right-wing political preference. The background characteristics balance across treatments 8

\section{Results}

This section provides an analysis of the redistribution decisions of the spectators. The distributive situations had substantial within-pair variation in the winner's and the loser's performance, which allows us to study the effect of the winning margin on the spectators' redistribution decisions.9

\subsection{Treatment Differences}

Figure 1 provides histograms of the share of income assigned to the winner for each treatment separately. The upper left panel shows the spectators' redistribution decisions in the WTA treatment and conveys a number of insights. First, in a winner-take-all situation, about 60 percent of the spectators accept the extreme inequality in earnings and do not redistribute at all. Second, a negligible share of spectators equalize income completely between the two workers. Third, spectators who do redistribute are clustered in the range of giving 60 to 70 percent of the earnings to the winner. Finally, very few spectators give more to the loser than to the winner, which provides strong evidence against many spectators making their distributive decision at random.

\footnotetext{
${ }^{6} \mathrm{We}$ did not use the terms winner and loser in the instructions but instead neutrally referred to the workers as participant $\mathrm{X}$ and participant $\mathrm{Y}$.

${ }^{7}$ Workers performed equally well in 41 pairs. Since there is no winner in these cases, we do not include these pairs in our analysis.

${ }^{8}$ See Table A.1 in Appendix A for more details on the background characteristics. Data and code are available from https://www.github.com/fair-nhh/mmwinner/

${ }^{9}$ Figure A.1 and Figure A.2 in Appendix A show the performance and corresponding winning margin for the WTA treatments.
} 

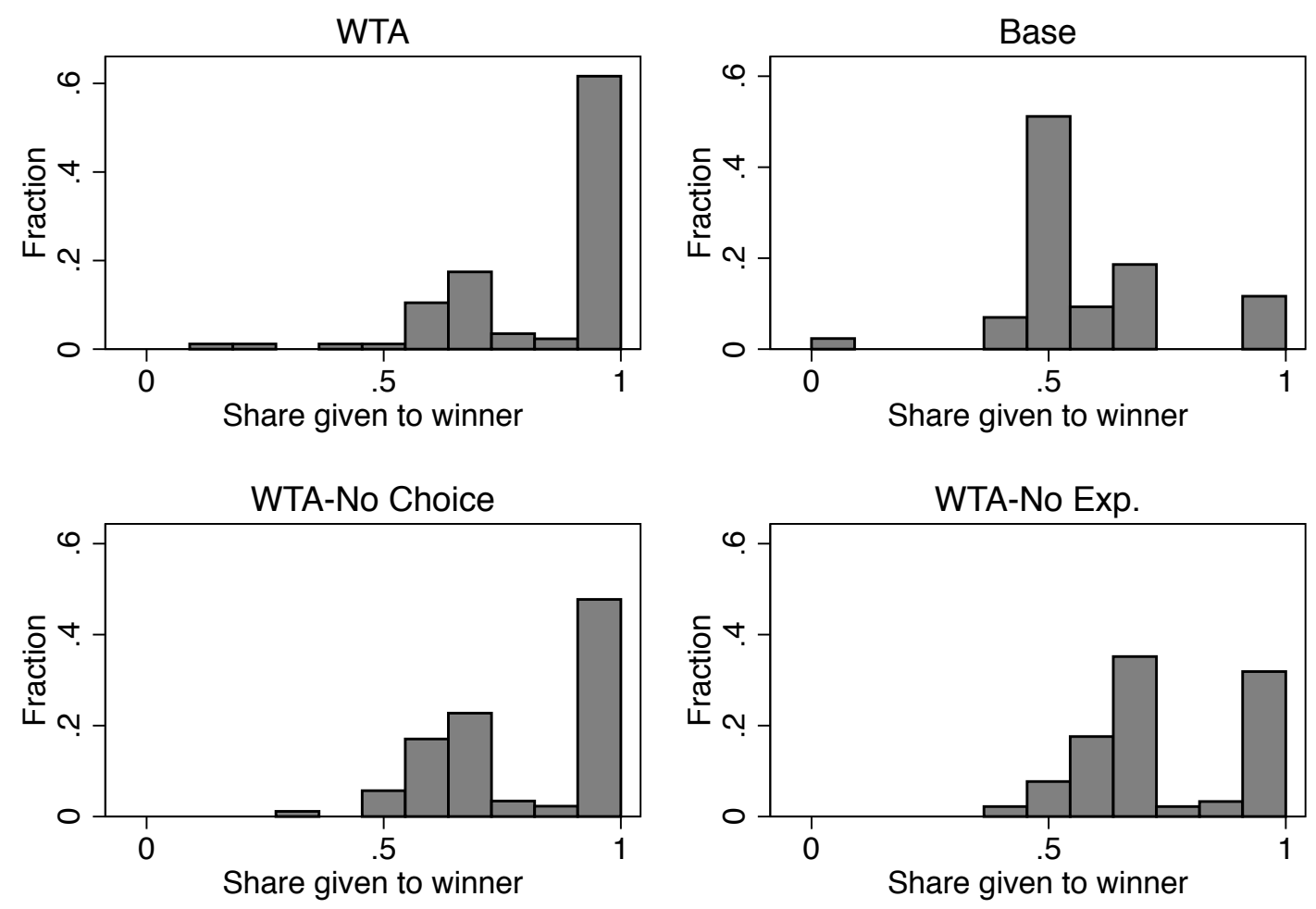

Figure 1: Share to winner. The panels show the distribution of the share of income assigned to the winner, by treatment

The upper right panel reveals that redistribution decisions are strikingly different in the Base treatment where the initial extreme inequality originates from luck. In contrast to the winnertake-all situation, only about ten percent of the spectators give everything to the winner, while the majority of spectators equalize completely.

The lower panels show the spectator decisions in the treatments WTA-No Choice and WTANo Expectations. We observe that the qualitative patterns are identical to the WTA treatment: a large share of spectators do not redistribute at all, very few equalize completely, and a significant share assign between 60 and 70 percent of the earnings to the winner. The acceptance of extreme inequality in the winner-take-all situation is thus not primarily driven by the fact that the workers chose to enter into competition and were aware of the winner-take-all reward structure. However, we find that the distribution in the lower panels shifts to the left compared to those of the WTA treatment, which suggests that spectators consider extreme inequality even more acceptable when the workers have made a choice and expect this reward structure.

Table 2 reports the corresponding OLS regressions, where we consider two dependent vari- 
ables: the share of income assigned to the winner ("Share to winner") and the fraction of spectators assigning all the income to the winner ("All to winner"). The models use the Base treatment as omitted category and regress the respective dependent variable on the treatment dummies WTA, WTA-No Choice, and WTA-No Expectations, with and without controlling for background characteristics and session fixed effects.

Table 2: Regression results: Treatment effects

\begin{tabular}{|c|c|c|c|c|}
\hline \multirow[b]{2}{*}{ WTA } & \multicolumn{2}{|c|}{ Share to winner } & \multicolumn{2}{|c|}{ All to winner } \\
\hline & $\begin{array}{c}0.273 \\
(0.036)\end{array}$ & $\begin{array}{c}0.275 \\
(0.037)\end{array}$ & $\begin{array}{c}0.465 \\
(0.073)\end{array}$ & $\begin{array}{c}0.472 \\
(0.075)\end{array}$ \\
\hline WTA-No Choice & $\begin{array}{c}0.221 \\
(0.036)\end{array}$ & $\begin{array}{c}0.223 \\
(0.036)\end{array}$ & $\begin{array}{c}0.361 \\
(0.073)\end{array}$ & $\begin{array}{c}0.367 \\
(0.074)\end{array}$ \\
\hline WTA-No Exp. & $\begin{array}{c}0.166 \\
(0.035)\end{array}$ & $\begin{array}{c}0.170 \\
(0.036)\end{array}$ & $\begin{array}{c}0.202 \\
(0.070)\end{array}$ & $\begin{array}{c}0.216 \\
(0.073)\end{array}$ \\
\hline Age & & $\begin{array}{c}0.001 \\
(0.005)\end{array}$ & & $\begin{array}{c}-0.001 \\
(0.013)\end{array}$ \\
\hline Female & & $\begin{array}{l}-0.019 \\
(0.023)\end{array}$ & & $\begin{array}{l}-0.035 \\
(0.057)\end{array}$ \\
\hline Right-wing & & $\begin{array}{c}0.008 \\
(0.023)\end{array}$ & & $\begin{array}{c}0.024 \\
(0.057)\end{array}$ \\
\hline Session FE & & $X$ & & $X$ \\
\hline Dep. Mean: Base & 0.587 & 0.587 & 0.116 & 0.116 \\
\hline$P:$ WTA = WTA-No Choice & 0.079 & 0.087 & 0.170 & 0.177 \\
\hline$P:$ WTA = WTA-No Exp. & 0.000 & 0.001 & 0.000 & 0.001 \\
\hline$P$ : WTA-No Choice = WTA-No Exp. & 0.060 & 0.079 & 0.030 & 0.044 \\
\hline$N$ & 308 & 308 & 308 & 308 \\
\hline$R^{2}$ adj. & 0.160 & 0.149 & 0.090 & 0.076 \\
\hline
\end{tabular}

Notes: The table reports linear regressions of the variables "Share to winner: share of income allocated to the winner by the spectator" and "All to winner": indicator variable taking the value one if the spectator assigned all the income to the winner on treatment indicator variables and a set of control variables (Age: spectator age in years, Female: indicator variable taking the value one if the spectator is a female, Right-wing: indicator variable taking the value one if the spectator self-reports to be either somewhat or very right-wing on a five-point political scale). Robust standard errors in parentheses.

The regression results confirm that the level of inequality acceptance differs significantly 
between the WTA treatment and the Base treatment. A winner in the WTA treatment receives a significantly larger share of the income (86 percent versus 59 percent, $p<0.01$ ) and is significantly more likely to receive all the earnings (59 percent versus 12 percent, $p<0.01$ ) than a winner in the Base treatment. These results are robust to the inclusion of the spectators' individual background characteristics and session fixed effects. We can thus state our first main finding.

Result 1: The majority of spectators accept extreme income inequality in a winner-takeall situation and do not redistribute at all, while the majority fully equalize incomes when the winner is randomly determined.

Qualitatively similar and highly statistically significant differences prevail when we compare redistribution decisions in the Base treatment to the treatments WTA-No Choice and WTANo Expectations, respectively. Also in these treatments, the winner receives a much larger share of the income $(p<0.01)$ and is much more likely to receive all the income $(p<0.01)$. But we observe that the inequality acceptance is significantly lower in these treatments than in the WTA treatment. In particular, the difference between WTA and WTA-No Expectations is highly significant both for the share of income assigned to the winner $(p<0.01)$ and for the share of spectators giving all the income to winner $(p<0.01)$. We thus find clear evidence that inequality acceptance in winner-take-all situations is affected by both choice and expectations.

Result 2: Spectators are significantly less likely to accept extreme income inequality if the workers have not chosen to work in a winner-take-all situation and are not aware of the winner-take-all reward structure.

To summarize, our data reveal a high degree of acceptance of extreme income inequality under winner-take-all reward structures when performance determines the winner. Self-selection into the winner-take-all reward structure and workers' being aware of the winner-take-all structure contribute to the inequality acceptance. In contrast, when luck determines the winner, there is almost no acceptance of inequality and incomes are fully equalized in the majority of cases.

\subsection{Fairness: Counterfactual versus Factual Merit}

We now turn to an analysis of which fairness argument shapes the spectator choices, where we first consider how spectator choices relate to the winning margin. If spectators apply a "factual 
merit" fairness argument and consider that the winner deserves all the earnings since these earnings were determined by his or her performance, then the winning margin should not affect the spectators' choices: the winner should get all the income. In contrast, if spectators apply a "counterfactual merit" fairness argument, and consider that the loser deserves an equal share of the earnings that would have been assigned to the loser had the winner not produced anything, then the share of income assigned to the winner should increase in the winning margin.

The upper panel in Figure 2 plots the mean share of income assigned to the winner as a function of the winning margin, pooled for the three WTA treatments where performance determines the winner. The lower panel plots the mean share of spectators who give all to the winner as a function of the winning margin $\sqrt{10}$ The figure suggests that the "factual merit" fairness argument is more prominent among the spectators than the "counterfactual merit" fairness argument: the winning margin neither appears to have a strong effect on the share given to the winner (upper panel) nor on the share of spectators giving everything to the winner (lower panel). The lower panel in Figure 2 suggests that about 50 percent of the spectators fully endorse the "factual merit" fairness argument.

Figure 3 plots the average income assigned to the winner as a function of the performance of the winner and the average income assigned to the loser as a function of the performance of the loser, where incomes are normalized to a piece-rate of one monetary unit for each correctly solved problem. Given this normalization, the "factual merit" fairness argument implies that there should be a proportional relationship between performance and income for the winner (as indicated by the 45-degree line), while the "counterfactual merit" fairness argument implies that a one point increase in performance of the loser should translate into a 0.5 point increase in income for the loser (as indicated by the 22.5-degree line). The left panel provides strong evidence in favor of the "factual merit" fairness argument: the estimated linear relationship between performance and income for the winner is not statistically significantly different from one (coefficient: 0.94, $p=0.36$, see Table A.2 in Appendix A). At the same time, in the right panel, we can clearly reject the prediction of the "counterfactual merit" fairness argument: the loser's income curve is almost entirely flat and the slope is significantly different from 0.5 (coefficient: 0.09, $p<0.001$, see Table A.2 in Appendix A). Rather, it appears that the losers, on average, receive a fixed "consolation prize," irrespective of their performance.

We can summarize this analysis by the following result:

\footnotetext{
${ }^{10}$ Figures A.3 and A.4 in Appendix A show that the same patterns prevail if we consider treatments WTA, WTA-No Choice, and WTA-No Expectations separately.
} 

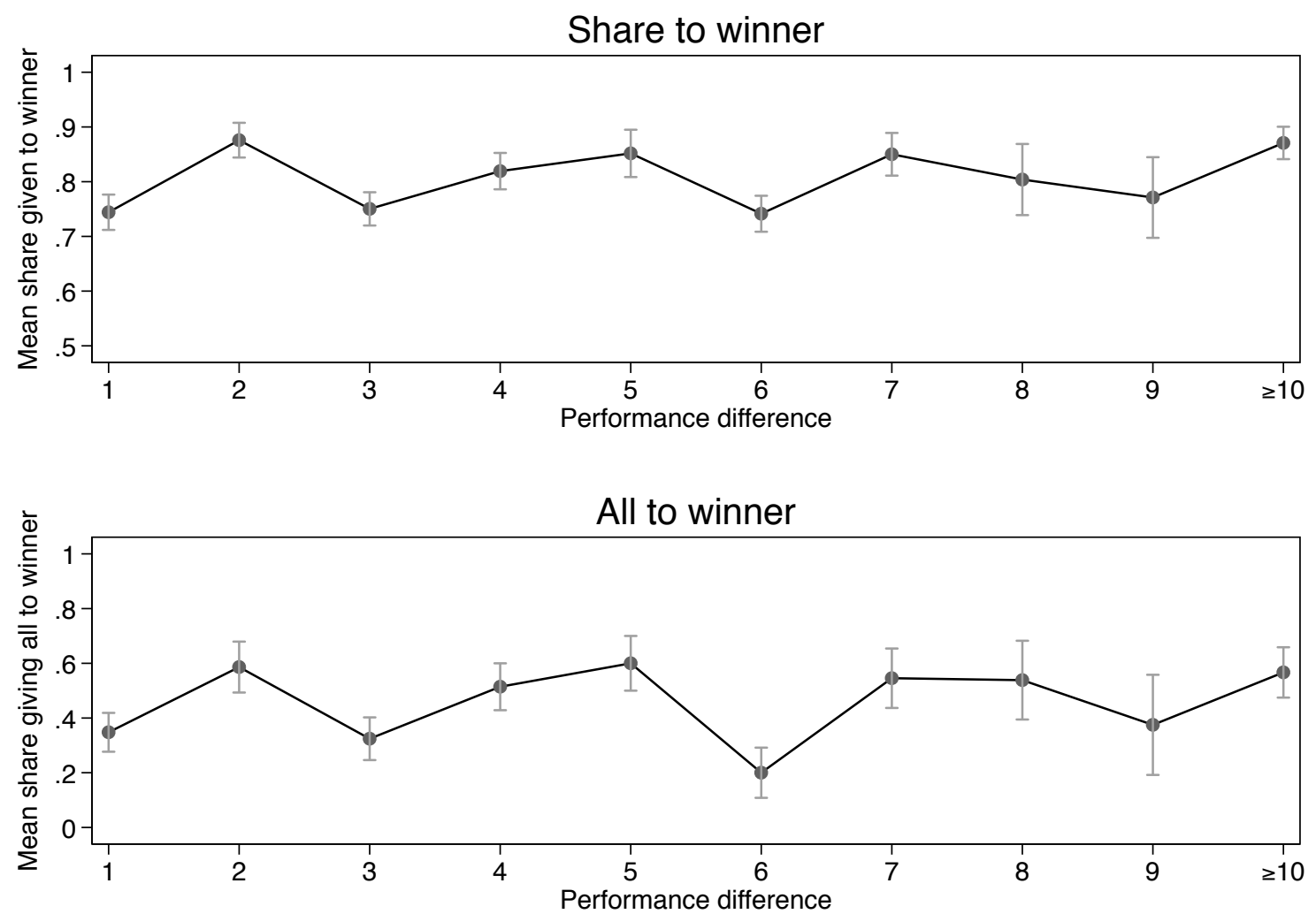

Figure 2: The winning margin. The upper panel shows the mean share of income assigned to the winner as a function of the difference in performance (measured by number of problems solved) between the winner and the loser. The lower panels shows the corresponding figure for the share of spectators assigning all the income to the winner. Bars show the standard errors of the means.

Result 3: Spectators largely endorse the "factual merit" fairness argument in a winnertake-all situation. The redistribution taking place appears to reflect that spectators give the loser a fixed "consolation prize," irrespective of the winning margin.

\section{Conclusions}

A main focus in the inequality debate has been on the increasing income inequality in many societies across the world, in particular that the top one percent of income earners receive a disproportionate share of the income in society. This has generated a call for more redistribution in the policy debate (Atkinson et al., 2011), while others have argued that this development is fair since the top income earners have earned their income by contributing to society (Mankiw, 2010).

We report from the first experimental study of people's fairness views on extreme income 

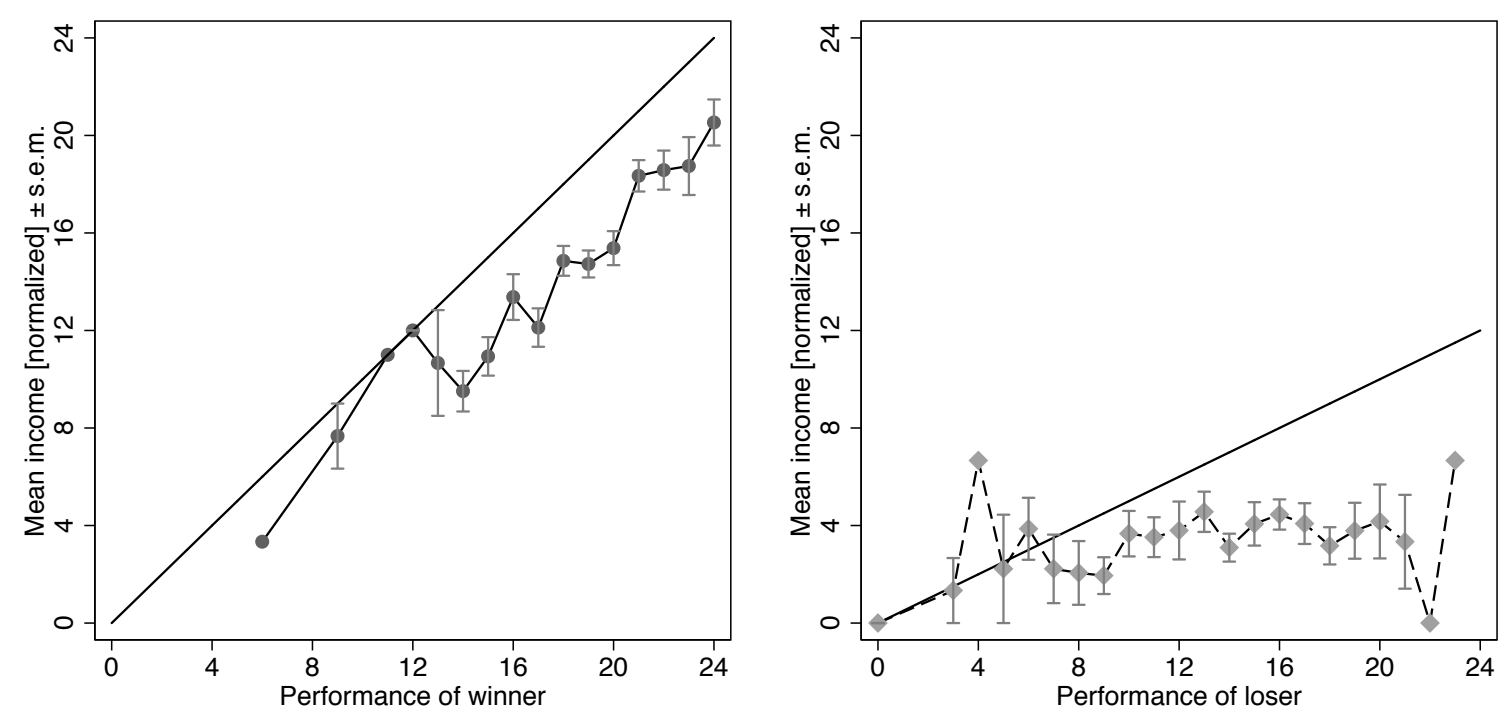

Figure 3: Income to winner and loser. The graphs show the average income assigned to the winner as a function of the winner's performance (measured by number of problems solved) and the average income assigned to the loser as a function of the loser's performance, pooled for all the WTA treatments. The incomes shown are normalized to a piece-rate of one monetary unit for each correctly solved problem. Bars show the standard errors of the means. The solid lines show the predications of the "factual merit" fairness argument (left panel) and the "counterfactual merit" fairness argument. Missing error bars indicate cases with a single observation only.

inequality, where we focus on the winner-take-all reward scheme, since the increasing prevalence of winner-take-all markets appears to be one of the driving factors behind the increasing income inequality in modern societies (Atkinson et al., 2011). Our data suggest that people do indeed seem to endorse extreme income inequalities which originate from a winner-take-all situation, while they object to the same inequalities when they reflect luck. We also provide evidence suggesting that the people invoke a "factual merit" fairness argument in their distributive decisions, where they consider the winner to deserve all the earnings since these earnings derive from his or her performance. We do not find support for the "counterfactual merit" fairness argument that the fair inequality between the winner and the loser corresponds to the additional earnings derived from the winning margin.

We believe that our findings can shed light on the recent inequality debate, by showing that it is not at all obvious that people find the increasing income inequality driven by the top income distribution unfair. At the same time, we believe that an interesting avenue for future research is to better understand the mechanisms underlying our findings. In particular, why are people not attracted to the "counterfactual merit" fairness argument, which would call for 
significant redistribution of income in many winner-take-all situations? Do people fundamentally object to this fairness argument or is it rather that the "factual merit" fairness argument is more salient in winner-take-all situations? Given that the "factual" and "counterfactual merit" fairness arguments have very different implications for the current political debate on inequality and redistribution, we consider it of great importance to study further the prevalence and foundation of these fairness arguments.

\section{References}

Adams, Stacy J. (1965). "Inequity in social exchange," Advances in Experimental Social Psychology, 2: 267-299.

Alesina, Alberto and Paola Giuliano (2011). "Preferences for redistribution," in Jess Benhabib, Alberto Bisin, and Matthew O Jackson (eds.), "Handbook of Social Economics," volume 1, chapter 4, Amsterdam, NL: Elsevier, pp. 99-131.

Almås, Ingvild, Alexander W. Cappelen, Kjell G. Salvanes, Erik Ø. Sørensen, and Bertil Tungodden (2016). "Willingness to compete: Family matters," Management Science, 62(8): 2149-2162.

Almås, Ingvild, Alexander W. Cappelen, Erik Ø. Sørensen, and Bertil Tungodden (2010). "Fairness and the development of inequality acceptance," Science, 328(5982): 1176-1178.

Alvaredo, Facundo, Anthony B. Atkinson, Thomas Piketty, and Emmanuel Saez (2013). "The top 1 percent in international and historical perspective," Journal of Economic Perspectives, 27(3): 3-20.

Atkinson, Anthony, Thomas Piketty, and Emanuel Saez (2011). "Top incomes in the long run of history," Journal of Economic Literature, 49(1): 3-71.

Bartling, Björn, Roberto A. Weber, and Lan Yao (2015). "Do markets erode social responsibility?" Quarterly Journal of Economics, 130(1): 219-266.

Buser, Thomas, Muriel Niederle, and Hessel Oosterbeek (2014). "Gender, competitiveness and career choices," Quarterly Journal of Economics, 129(3): 1409-1447. 
Cabrales, Antonio, Raffaele Miniaci, Marco Piovesan, and Giovanni Ponti (2010). "Social preferences and strategic uncertainty: An experiment on markets and contracts," American Economic Review, 100: 2261-2278.

Cappelen, Alexander W., Astri Drange Hole, Erik Ø. Sørensen, and Bertil Tungodden (2007). "The pluralism of fairness ideals: An experimental approach," American Economic Review, 97(3): 818-827.

Cappelen, Alexander W., James Konow, Erik Ø. Sørensen, and Bertil Tungodden (2013a). "Just luck: An experimental study of risk taking and fairness," American Economic Review, 103(3): 1398-1413.

Cappelen, Alexander W., Karl O. Moene, Erik Ø. Sørensen, and Bertil Tungodden (2013b). "Needs versus entitlements: An international fairness experiment," Journal of the European Economic Association, 11(3): 574-598.

Cappelen, Alexander W., Erik Ø. Sørensen, and Bertil Tungodden (2010). "Responsibility for what? Fairness and individual responsibility," European Economic Review, 54(3): 429-441.

Cherry, Todd L., Peter Frykblom, and Jason F. Shogren (2002). "Hardnose the dictator," American Economic Review, 92(4): 1218-1221.

Durante, Ruben, Louis Putterman, and Joël Weele (2014). "Preferences for redistribution and perception of fairness: An experimental study," Journal of the European Economic Association, 12(4): 1059-1086.

Falk, Armin, Ernst Fehr, and Urs Fischbacher (2003). "On the nature of fair behavior," Economic Inquiry, 41(1): 20-26.

Fehr, Ernst and Klaus M. Schmidt (1999). "A theory of fairness, competition and cooperation,” Quarterly Journal of Economics, 114(3): 817-868.

Fong, Christina (2001). "Social preferences, self-interest, and the demand for redistribution," Journal of Public Economics, 82(2): 225-246.

Frank, Robert and Philip J. Cook (1995). The Winner-Take-All Society: Why the Few at the Top Get So Much More Than the Rest of Us, New York, NY: Penguin Books. 
Frohlich, Norman, Joe Oppenheimer, and Anja Kurki (2004). "Modeling other-regarding preferences and an experimental test," Public Choice, 119(1-2): 91-117.

Gneezy, Uri and Aldo Rustichini (2004). “Gender and competition at a young age," American Economic Review, 94(2): 378-381.

Jakiela, Pamela (2015). "How fair shares compare: Experimental evidence from two cultures," Journal of Economic Behavior \& Organization, 118: 40-54.

Konow, James (2000). "Fair Shares: Accountability and Cognitive Dissonance in Allocation Decisions," American Economic Review, 90(4): 1072-1091.

Konow, James, Tatsuyoshi Saijo, and Kenju Akai (2009). "Morals and mores? Experimental evidence on equity and equality," Mimeo, Loyola Marymount University.

Leventhal, Gerald S. (1980). What Should Be Done with Equity Theory?, chapter 2, Springer, pp. 27-55.

Mankiw, Gregory N. (2010). "Spreading the wealth around: Reflections inspired by joe the plumber," Eastern Economic Journal, 36(3): 285-298.

Mankiw, N Gregory (2013). "Defending the one percent," Journal of Economic Perspectives, 27(3): 21-34.

Marshall, Alfred (1920). Principles of Economics, London: Macmillan and Co., Ltd., 8 edition.

Mollerstrom, Johanna, Bjorn-Atle Reme, and Erik Ø. Sørensen (2015). "Luck, choice and responsibility: An experimental study of fairness views," Journal of Public Economics, 131: $33-40$.

Niederle, Muriel and Lise Vesterlund (2007). "Do women shy away from competition? Do men compete too much?" Quarterly Journal of Economics, 122(3): 1067-1101.

Piketty, Thomas and Emmanuel Saez (2003). "Income inequality in the United States, 19131998," Quarterly Journal of Economics, 118(1): 1-39.

Rodriguez-Lara, Ismael and Luis Moreno-Garrido (2012). "Self-interest and fairness: selfserving choices of justice principles," Experimental Economics, 15(1): 158-175. 
Rosen, Sherwin (1981). "The economics of superstars," American Economic Review, 71(5): $845-858$.

Samek, Anya C. (2013). 'Is there a gender gap in preschoolers' competitiveness? an experiment in the U.S," Journal of Economic Behavior \& Organization, 92: 22-31.

Tyran, Jean-Robert and Robert Sausgruber (2006). "A little fairness may induce a lot of redistribution in democracy," European Economic Review, 50(2): 469-485.

Walster, Elaine, Ellen Berscheid, and William G. Walster (1973). "New directions in equity research," Journal of Personality and Social Pscychology, 25(2): 151-176. 


\section{A Online appendix: Supplementary Figures and Tables}

Data, and also replication code to produce the analysis in the paper, are openly available at https://www .github.com/fair-nhh/mmwinner/. In order to protect individual participants from risk of backward identification, we put the individuals with lowest and the highest ages reported together in groups, and replaced actual age with group average ages. Details on the procedure and also on the effect of this procedure on the regressions reported in Table 2 are available on the Github site mentioned above. The effects were very minor (third digits).

Table A.1: Randomization into Treatments

\begin{tabular}{|c|c|c|c|c|c|c|}
\hline & \multirow[b]{2}{*}{ All } & \multicolumn{3}{|c|}{ WTA } & \multirow[b]{2}{*}{ Base } & \multirow[b]{2}{*}{$F-t e s t$} \\
\hline & & Main & No Choice & No Exp. & & \\
\hline Age & 21.98 & 22.23 & 22.06 & 21.74 & 21.76 & 0.370 \\
\hline Female & .416 & .372 & .489 & .429 & .326 & 0.247 \\
\hline Right wing & .594 & .558 & .568 & .637 & .628 & 0.656 \\
\hline$N$ & 308 & 86 & 88 & 91 & 43 & 308 \\
\hline
\end{tabular}


Table A.2: Regression results: Counterfactual versus Factual Merit

\begin{tabular}{|c|c|c|}
\hline & Income to winner & Income to loser \\
\hline Performance winner & $\begin{array}{cc}0.939 & 0.938 \\
(0.066) & (0.068)\end{array}$ & \\
\hline
\end{tabular}

Performance loser

$0.100 \quad 0.088$

(0.052) (0.051)

\begin{tabular}{|c|c|c|c|c|}
\hline Age & & $\begin{array}{c}0.126 \\
(0.114)\end{array}$ & & $\begin{array}{l}-0.118 \\
(0.112)\end{array}$ \\
\hline Female & & $\begin{array}{l}-0.537 \\
(0.484)\end{array}$ & & $\begin{array}{c}0.504 \\
(0.475)\end{array}$ \\
\hline Right-wing & & $\begin{array}{l}-0.129 \\
(0.474)\end{array}$ & & $\begin{array}{c}0.124 \\
(0.471)\end{array}$ \\
\hline Session FE & & $X$ & & $X$ \\
\hline Constant & $\begin{array}{l}-2.446 \\
(1.238)\end{array}$ & & $\begin{array}{c}2.204 \\
(0.718)\end{array}$ & \\
\hline$N$ & 265 & 265 & 265 & 265 \\
\hline$R^{2}$ adj. & 0.403 & 0.403 & 0.008 & 0.005 \\
\hline
\end{tabular}

Notes: The table reports linear regressions of the variables "Income to winner: income allocated to the winner by the spectator" and "Income to loser: income allocated to the loser by the spectator" on the performance of the winner and loser respectively and a set of control variables (Age: spectator age in years, Female: indicator variable taking the value one if the spectator is a female, Right-wing: indicator variable taking the value one if the spectator self-reports to be either somewhat or very right-wing on a five-point political scale). Robust standard errors in parentheses. 

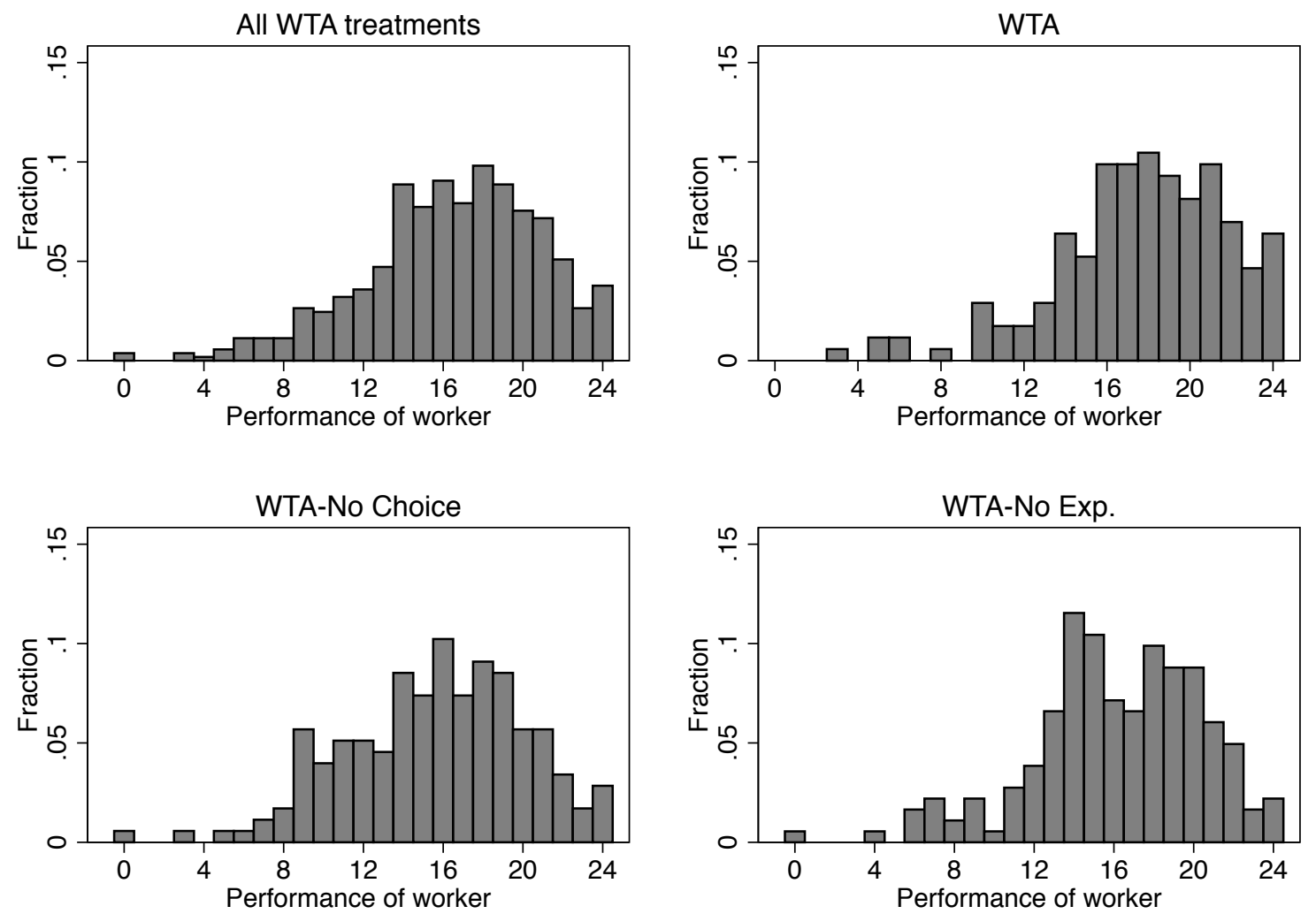

Figure A.1: Performance of workers by treatment. Data from the Base treatment are excluded because spectators did not receive performance information in that treatment. 

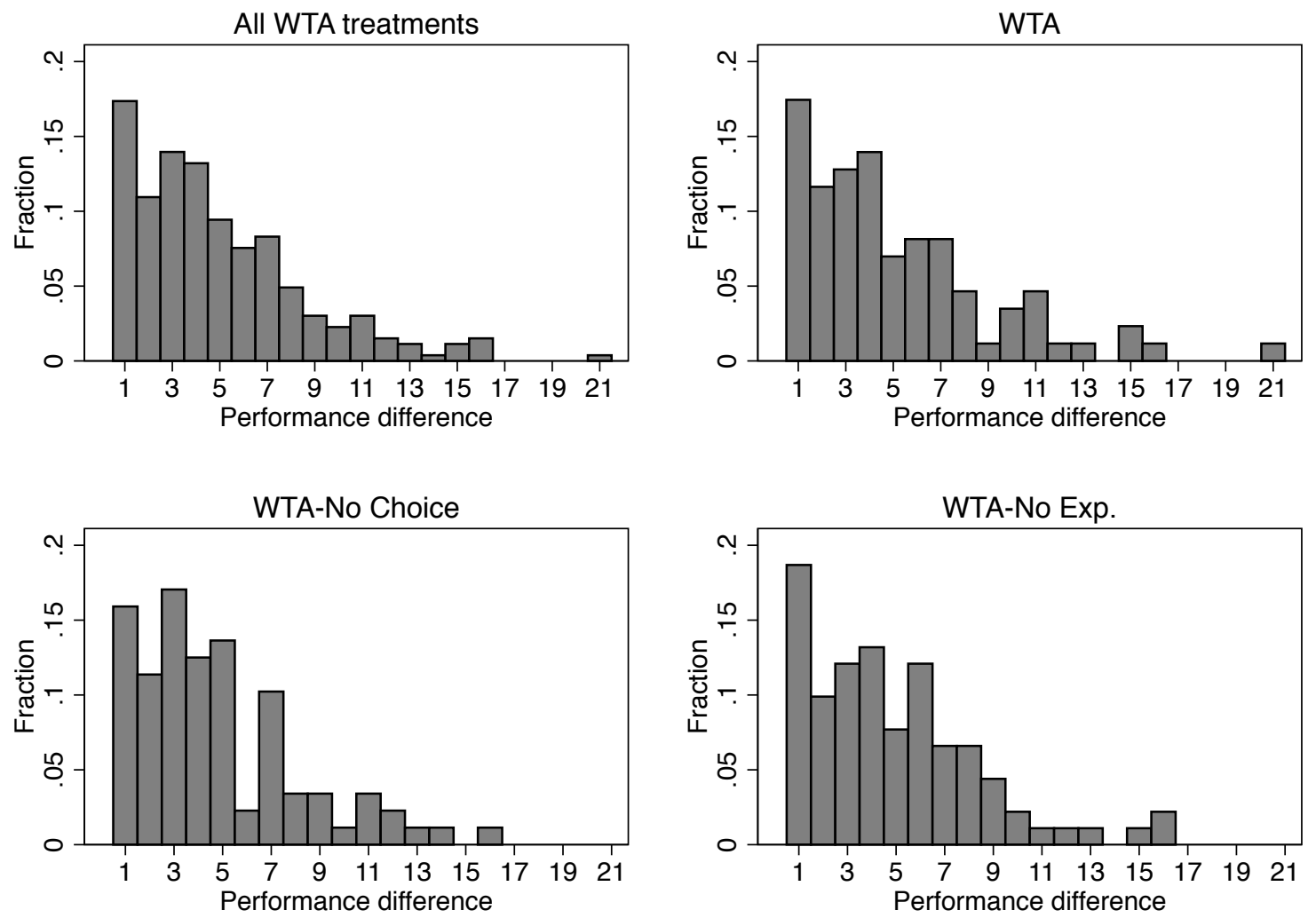

Figure A.2: Performance difference by treatment. Data from the Base treatment are excluded because spectators did not receive performance information in that treatment. 


\section{Share to winner}
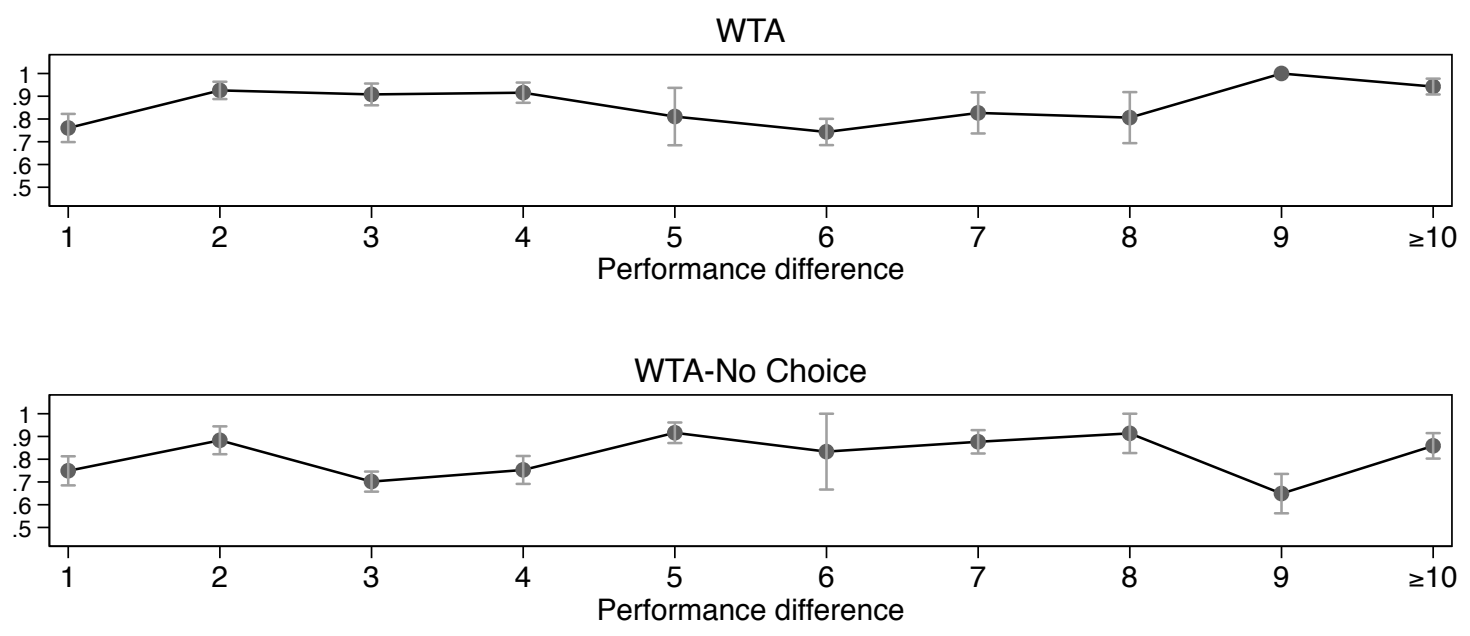

WTA-No Expectations

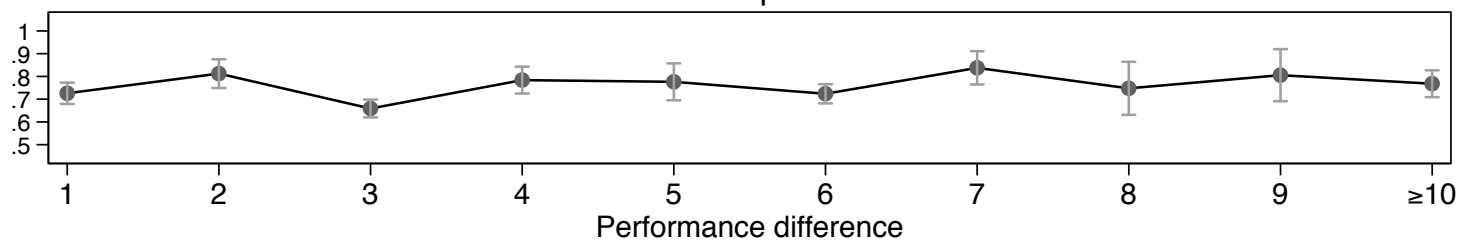

Figure A.3: The winning margin by treatment (share given to winner) 


\section{All to winner}

WTA

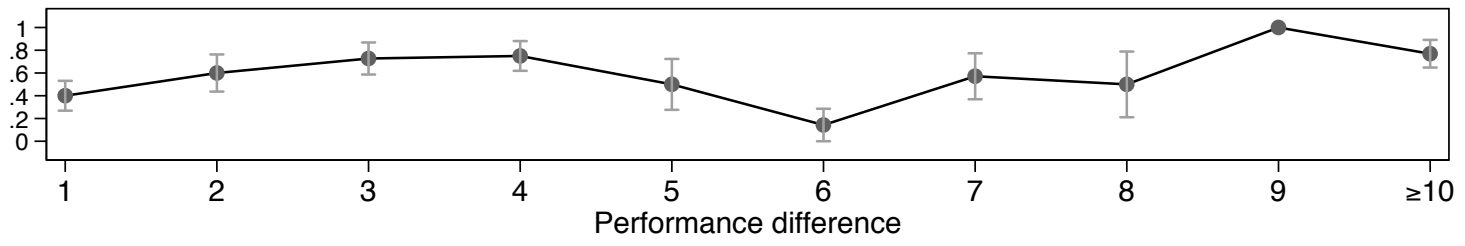

WTA-No Choice

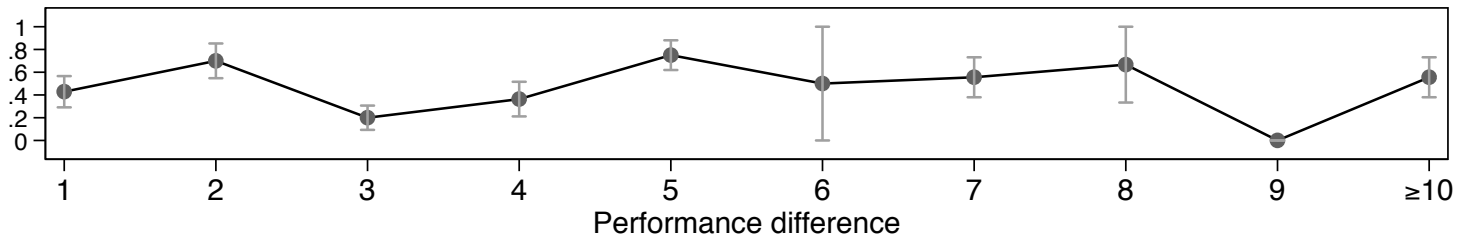

WTA-No Expectations

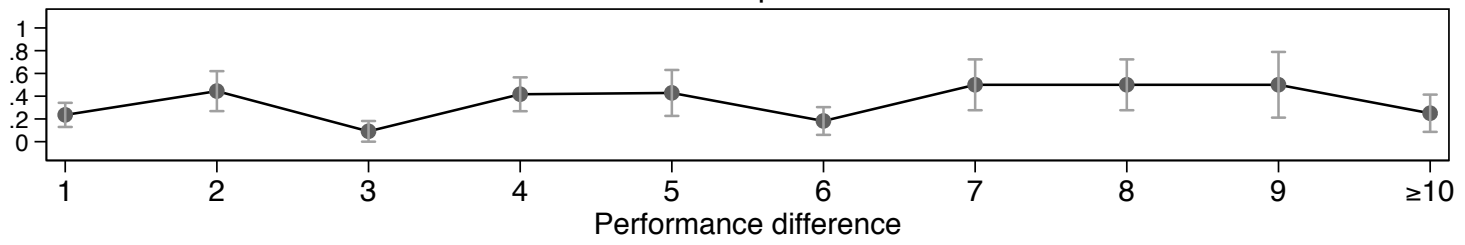

Figure A.4: The winning margin by treatment (share giving all to winner) 


\section{B Online appendix: Experimental Instructions}

\section{B.1 General instructions to workers (first screen)}

In this study you will perform a pattern recognition task. The task is to decide which figure is missing based on a logical pattern. This pattern is present in both a horizontal and a vertical direction. Below you can see two example questions and the correct answers.
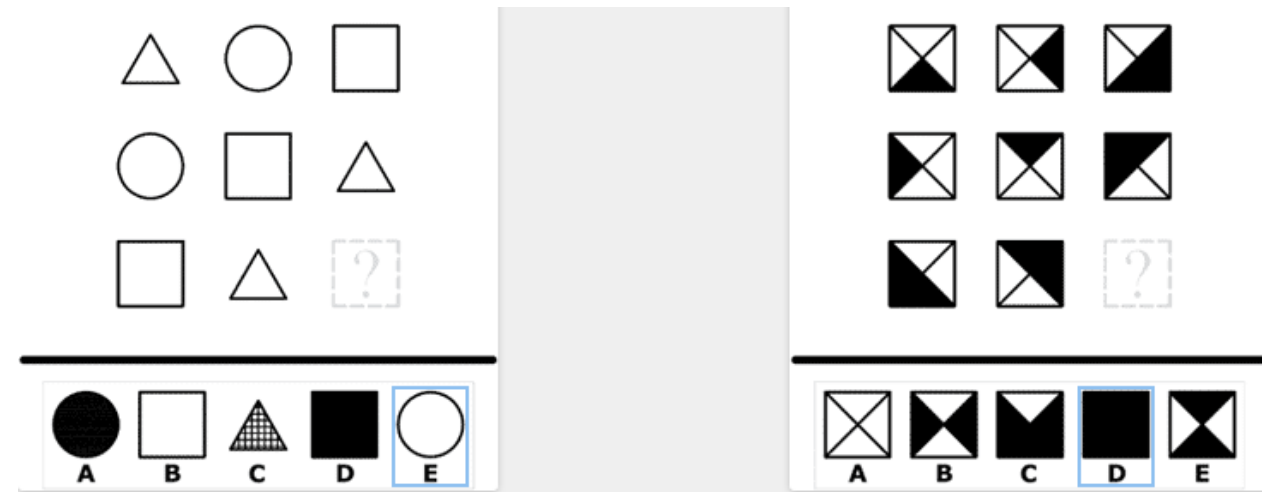

In total the task consists of 24 problems and you will have 10 minutes to record your answers.

On the next screen, we will give you some further information before you start on the task. 


\section{B.2 Specific instructions to workers (second screen): Treatment WTA}

You can choose between two options for earning bonus points on the task:

Option A: You earn 5 bonus points for every correct answer in the pattern recognition task.

Option B: You will be paired with another, randomly determined, participant in the study. Both of you will perform the exact same task. You will earn:

- 15 bonus points for every correct answer if you solve at least as many problems as the other participant.

- 0 bonus points if you solve fewer problems than the other participant.

After your earnings of bonus points are determined, there will be another phase (which you will not take part in) that may affect the final distribution of bonus points between you and the other participant.

Please choose option for earnings:

Option A

Option B

When you press the button below the pattern recognition task will start and you will have 10 minutes to record your answers.

Good luck! 


\section{B.3 Specific instructions to workers (second screen): Treatment WTA-No Choice}

You will be paired with another, randomly determined, participant in the study. Both of you will perform the exact same task. You will earn:

- 15 bonus points for every correct answer if you solve at least as many problems as the other participant.

- 0 bonus points if you solve fewer problems than the other participant.

After your earnings of bonus points are determined, there will be a final phase (which you will not take part in) that may affect the distribution of bonus points between you and the other participant.

When you press the button below the pattern recognition task will start and you will have 10 minutes to record your answers.

Good luck!

\section{B.4 Specific instructions to workers (second screen): Treatment WTA-No Expectations}

When you press the button below the pattern recognition task will start and you will have 10 minutes to record your answers.

Good luck!

\section{B.5 Specific instructions to workers (second screen): Treatment Base}

When you press the button below the pattern recognition task will start and you will have 10 minutes to record your answers.

Good luck! 


\section{B.6 Specific instructions to spectators: Treatment WTA}

\section{Background}

In another study we have conducted, participants were asked to solve 24 pattern recognition problems in 10 minutes. Before doing the task the participant could choose how he or she wanted the earnings for the task to be determined. The participant had two options:

Option A: The participant would be paid 5 cents for every correct answer.

Option B: The participant would be paired with another, randomly determined, participant in the study that also chose option B and his or her earnings would then be determined as follows:

- 15 cents for every correct answer if the participant solved at least as many problems as the other participant.

- Nothing if the participant solved fewer problems than the other participant.

The participants were also told that if they chose option B, there would be a final phase (which they would not take part in) that might affect the distribution of bonus points between the two participants, and thereby also how much they were paid for the task. The participants were not given any further information after completing the task. The only feedback each participant will receive from the study is the amount of money that is paid out to him or her.

\section{Your choice}

You are to be the decision maker in the final phase for one pair of participants, here referred to as participant $\mathrm{X}$ and participant $\mathrm{Y}$, who both chose option B.Participant $\mathrm{X}$ solved $\mathrm{x} 1$ problems and participant $\mathrm{Y}$ solved $\mathrm{x} 2$ problems. Hence, participant X earned e1 USD and participant Y earned e2 USD. You are now to determine whether there should be any redistribution of earnings between person $\mathrm{X}$ and person $\mathrm{Y}$. If you decide not to redistribute anything, person $\mathrm{X}$ will be paid e1 USD and person Y will be paid e2 USD for the task.

Remember that this is a real choice; your choice will determine how much two individuals are paid for doing this task. 


\section{B.7 Specific instructions to spectators: Treatment WTA-No Choice}

\section{Background}

In another study we have conducted, participants were asked to solve 24 pattern recognition problems in 10 minutes. Before doing the task, the participant was told that he or she would be paired with another, randomly determined, participant in the study and that his or her earnings would be determined as follows:

- 15 cents for every correct answer if the participant solved at least as many problems as the other participant.

- Nothing if the participant solved fewer problems than the other participant.

The participants were also told that there would be a final phase (which they would not take part in) that might affect the distribution of bonus points between the two participants, and thereby also how much they were paid for the task.

The participants were not given any further information after completing the task. The only feedback each participant will receive from the study is the amount of money that is paid out to him or her.

\section{Your choice}

You are to be the decision maker in this final phase for one pair of participants, here referred to as participant $\mathrm{X}$ and participant $\mathrm{Y}$. Participant $\mathrm{X}$ solved $\mathrm{x} 1$ problems and participant $\mathrm{Y}$ solved x2 problems. Hence, participant X earned e1 USD and participant $Y$ earned e2 USD. You are now to determine whether there should be any redistribution of earnings between person $\mathrm{X}$ and person Y. If you decide not to redistribute anything, person X will be paid e1 USD and person Y will be paid e2 USD for the task.

Remember that this is a real choice; your choice will determine how much two individuals are paid for doing this task. 


\section{B.8 Specific instructions to spectators: Treatment WTA-No Expectations}

\section{Background}

In another study we have conducted, participants were asked to solve 24 pattern recognition problems in 10 minutes. The participants were not at any point told that they would receive payment for doing the task. The only feedback the participants will receive from that study is the amount of money that is paid out to him or her.

The payment to each participant will be determined in two steps. First, each participant is paired with another, randomly determined, participant in the study and his or her earnings are determined as follows:

- 15 cents for every correct answer if the participant solved at least as many problems as the other participant.

- Nothing if the participant solved fewer problems than the other participant.

Second, there will be a final phase were a third person will be given the opportunity to change the distribution of bonus points between the two participants, and thereby also how much they are paid for the task.

\section{Your choice}

You are to be the decision maker in this final phase for one pair of participants, here referred to as participant $\mathrm{X}$ and participant $\mathrm{Y}$. Participant $\mathrm{X}$ solved $\mathrm{x} 1$ problems and participant $\mathrm{Y}$ solved x2 problems. Hence, participant X earned e1 USD and participant $Y$ earned e2 USD. You are now to determine whether there should be any redistribution of earnings between person $\mathrm{X}$ and person Y. If you decide not to redistribute anything, person X will be paid e1 USD and person Y will be paid e2 USD for the task.

Remember that this is a real choice; your choice will determine how much two individuals are paid for doing this task. 


\section{B.9 Specific instructions to spectators: Treatment Base}

\section{Background}

In another study we have conducted, participants were asked to solve 24 pattern recognition problems in 10 minutes. The participants were not at any point told that they would receive payment for doing the task. The only feedback the participants will receive from that study is the amount of money that is paid out to him or her.

The payment to each participant will be determined in two steps. First, each participant is paired with another, randomly determined, participant in the study and then there is a random allocation procedure that determines the earnings for the two. This means that their performance did not at all influence their earnings. Second, there will be a final phase were a third person will be given the opportunity to change the distribution of bonus points between the two participants, and thereby also how much they are paid for the task.

\section{Your choice}

You are to be the decision maker in the final phase for one pair of participants, here referred to as participant $\mathrm{X}$ and participant $\mathrm{Y}$. Both participants completed the task. The random allocation procedure assigned e1 USD to participant X and e2 USD to participant Y. You are now to determine whether there should be any redistribution of earnings between person $\mathrm{X}$ and person Y. If you decide not to redistribute anything, person $\mathrm{X}$ will be paid e1 USD and person Y will be paid e2 USD for the task.

Remember that this is a real choice; your choice will determine how much two individuals are paid for doing this task. 